\title{
Annual Period Prevalence and Risk Factors of Dementia Among Older Jordanian Hospitalized Patients
}

This article was published in the following Dove Press journal: International Journal of General Medicine

\author{
Raid Kofahi (1D' \\ Ma'en Aljezawi $\mathbb{D}^{2}$ \\ Asem Abdalrahim ${ }^{2}$ \\ Mohammad Al Qadire ${ }^{3}$ \\ Deema Obiedat ${ }^{\prime}$ \\ Suha Aqaileh' \\ 'Jordan University of Science and \\ Technology, Faculty of Medicine, \\ Neuroscience Department, Irbid, Jordan; \\ ${ }^{2} \mathrm{Al}$ al-Bayt University, Mafraq, Jordan; \\ ${ }^{3}$ College of Nursing, Sultan Qaboos \\ University, Muscat, Oman
}

Background: The number of people living with dementia is forecasted to increase rapidly, particularly in developing and underdeveloped countries. No epidemiological studies of dementia have been reported in Jordan; therefore, the number of people living with dementia and the risk factors are unknown.

Objective: Measure the annual period prevalence of dementia, along with its risk factors in Jordanian hospitalized patients over the age of 50 years.

Methods: The prevalence of dementia was measured using a prospective survey design for over one year. Risk factors were explored using a case-control match design.

Results: The total number of participants in the overall survey was 31,411 , and the number of participants included as cases with dementia was 406 , the number of matched controls free of dementia was 416 . The general annual period prevalence of dementia for people older than 50 years was $1.29 \%$, comprising 406 patients. Multivariate analysis revealed that older age, male gender, family history of dementia, and illiteracy were significant risk factors for dementia.

Conclusion: The prevalence of dementia in Jordan is lower than the global prevalence due to the relatively younger Jordanian population. Results from this study can provide baseline information for policymakers for significant health planning to meet the needs of such a group of patients.

Keywords: prevalence, risk factors, dementia, Jordan, predictors

\section{Introduction}

In the contemporary health care industry, non-communicable diseases, including dementia, pose a significant health concern. ${ }^{1}$ Dementia is the clinical presentation of a number of neurodegenerative diseases, which include: Alzheimer's disease (AD), frontotemporal dementia, Lewy body dementia, and vascular dementia. ${ }^{2}$ Whatever the cause of dementia, the illness produces a decline in' cognitive and functional abilities that are not attributed to aging. ${ }^{3}$ Symptoms include but are not limited to: forgetfulness, confusion, decreased ability to concentrate, and psychotic symptoms. ${ }^{4}$ The onset of symptoms is usually at a late age ( $>65$ years); however, dementia can start at a younger age. ${ }^{5}$

\section{Risk Factors of Dementia}

Dementia can result from an interaction of comorbidities, genes, and the environment. Therefore, there are modifiable and non-modifiable risk factors. Comorbidities
Jordan University of Science an

Technology, Faculty of Medicine,

Neuroscience Department, PO. Box

3030, Irbid, 221 I0, Jordan

Tel +962796877750

Email rmkofahi@just.edu.jo
International Journal of General Medicine 2021:|4 64|-647

641

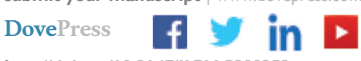

http://doi.org/10.214711/GM.S299353 
(eg diabetes, hypertension, atherosclerosis, obesity, and hyperlipidemia) are examples of modifiable risk factors that can be controlled. Other modifiable risk factors include illiteracy, lack of physical activity, and tobacco use. ${ }^{6}$ Research has proven that modifying these risk factors and controlling comorbidities by following a healthy lifestyle can prevent the appearance of dementia symptoms, especially of the AD type. ${ }^{7}$

There are also non-modifiable risk factors like ethnicity. A meta-analysis demonstrated that the highest incidence of dementia occurred in Latin America, and the lowest occurred in South Africa. ${ }^{2}$ Age also was reported to be one of the critical non-modifiable risk factors. Studies found that the risk of dementia increases in the age group 80-84 years and then starts to fall around 95 years. ${ }^{8}$ In this context, it is essential to know which factors put the population at risk of developing dementia in order to increase awareness and prevention.

\section{Prevalence of Dementia}

Worldwide, literature has reported different studies investigating dementia incidence and prevalence. For instance, one study conducted in the USA found that dementia prevalence ranged from 5\% for people aged 71-79 years to $37.4 \%$ for over 90 years. ${ }^{9}$ A more recent study in the same country found that the prevalence of dementia decreased from $12 \%$ in the year 2000 to $10.5 \%$ in the year 2012. ${ }^{10}$ In China and Hong Kong, an updated prevalence study revealed a total prevalence of 5.\% for those over 60 years old. ${ }^{11}$ Kalaria et al (2008) explored dementia in developing countries; they found that the prevalence of dementia for those over 65 years old was $\geq 5 \%$ in South America and Asia. This number dropped to $1-3 \%$ in India and sub-Saharan Africa. ${ }^{12}$

In general, trends of dementia epidemiology in developed countries show that there has been a stable to decreasing number of people with dementia in the last decade. ${ }^{13,14}$ Reversely, the number of people with dementia in poor or developing countries is expected to increase. This could be related to risk factors like illiteracy and comorbidities. $^{15}$

In the Middle East, few studies explored the prevalence of dementia. One study conducted in Israel to estimate the prevalence of dementia in people 60 years or older found the prevalence to be $6.6 \%$. The presence of dementia was associated with mental illnesses and ischemic heart disease. ${ }^{16}$ Another study conducted in an elderly Arab population in Israel found the prevalence of $\mathrm{AD}$ to be
20.5\%. Reasons for this high prevalence included: low socioeconomic status, illiteracy, and genetic factors. ${ }^{17}$

In a nutshell, the prevalence of dementia varied between studies due to different sampling methods and population risk factors that can strongly affect these figures. A knowledge gap exists in dementia epidemiology within low- and middle-income countries. In Jordan, to the best of our knowledge, no epidemiological studies have explored the incidence or prevalence of dementia. For this reason, this study was conducted to measure the annual period prevalence of dementia. Also, it was mentioned earlier that the prevalence of dementia increases with old age; the Jordanian population is considered relatively young compared to populations in developed countries, so this is another reason for this study.

\section{Methods \\ Design}

A prospective survey design was used to conduct the study in two referral hospitals. Risk factors were explored using a case-control match design.

\section{Setting and Participants}

The study was conducted in the largest two referral hospitals in the north of Jordan. Institutes where the work was conducted: King Abdullah University Hospital and Princess Basma Teaching Hospital. All patients aged 50 years or older admitted to the hospital over one year were included in the study, utilizing a convenience sampling technique. All Jordanian population in the north of Jordan have access to the two referral hospitals where the research was conducted through government sponsored insurances. The hospitals where the research was conducted are the only referral hospitals in the northern area of Jordan and serve a population of approximately 1.8 million. These hospitals undergo an external periodical accreditation process and follow strict quality measures. They also have an electronic medical record system that allows easy and accurate access to patients' data.

\section{Data Collection Procedure}

All patients aged 50 years or older admitted to the hospitals were surveyed for dementia over one year (from March 2019 until April 2020) to measure the annual period prevalence of dementia. Electronic medical records in the hospital were searched daily to identify any patients over the age of 50 with an entry of a cognitive impairment 
and/or confusion. In this incident, a qualified medical neurologist from the research team examined the patient to confirm or refute the diagnosis of dementia. The diagnosis was made through a semi-structured interview with the patient and caregiver by a qualified medical neurologist using the Diagnostic and Statistical Manual of Mental Disorders/Text Revision fourth edition (DSM-IV-TR). The severity of dementia was rated according to the Mini Mental State Examination (MMSE).

After a primary diagnosis of dementia was established, the DSM-IV-TR criteria were used to differentiate the pathological processes causing dementia, eg, AD, vascular dementia, frontotemporal, and so forth.

The recruited patients' evaluation also included demographical data (age, gender), marital status (married, single, divorced, widow/er), medical history (number of comorbidities eg Diabetes, Heart disease, brain attack, chronic obstructive pulmonary disease, arthritis), Body Mass Index (BMI), family history of dementia, literacy (literate. Illiterate), smoking behavior (never smoked, $\mathrm{X}$ smoker, smoker), and medical imaging if indicated to prove the presence of dementia and differentiate its type. Patients who had a reversible cognitive decline due to medications or any other acute illness like infection or metabolic derangements were excluded from the study. The patients were reevaluated by qualified medical neurologist several weeks after discharge in the clinic to confirm the diagnosis and type of dementia. All patients who did not meet the criteria for the diagnosis of dementia during the outpatient follow up were excluded from the study.

Written consent from patients to participate in the study was obtained; the consent was taken from the accompanying caregiver if the patient could not give consent. The consent form contains a brief description of the study, so patients or their caregivers can have a clear picture of their participation. All information obtained from each patient was recorded on an electronic data collection sheet made using Google Forms. To avoid patients being counted more than once, the medical record number was recorded for each patient. The primary investigator revised the collected data for completeness to avoid missing data.

To explore risk factors of dementia, patients with dementia were classified into four age groups (50-59 years, 60-69 years, 70-79 years, and 80-89 years). Each case of dementia was paired with a randomly selected control from the same age group but free of dementia or any reversible cognitive decline. Data from controls were collected using the same electronic sheet and following the same study procedure.

\section{Data Analysis}

Data were analyzed using IBM SPSS (version 26). Descriptive statistics (frequency, mean, standard deviation (SD)) were used to compute the prevalence rate and describe the study sample's characteristics. Univariate analysis ( $t$-test, Chi-square) was used to compare sample characteristics between patients with and without dementia. Multivariate analysis (logistic regression) was used to determine the risk factors of dementia. Alpha level of $\leq$ 0.05 was deemed to be significant.

\section{Results \\ Prevalence and Characteristics of Dementia Patients}

The total number of patients ( $\geq 50$ years) surveyed was 31,411 over one year in the two hospitals; of those, $61 \%$ were males, $57.4 \%$ were over the age of 65 years. A total of 406 had a confirmed diagnosis of dementia, giving an annual period prevalence of $1.29 \%$ (CI95\%: 0.011 to 0.014). The annual period prevalence of dementia for patients 65 years or older was 1.94\% (CI95\%: 0.017 to $0.021)$. Most of the dementia cases $(70.4 \%)$ were males. The mean age of patients with dementia was 74.4 years $(\mathrm{SD}=8.2)$. The youngest patient with dementia was aged 51 years, and the oldest was 89 years; nearly two-thirds of the patients $(67.6 \%)$ were aged 65 years or older (see Tables 1 and 2 for full details).

Most of the patients were married $(78.3 \%)$; the larger percentage $(69.5 \%)$ were literate; $78.8 \%$ of patients were current smokers or had been smoking for at least ten years. The mean body mass index for dementia patients was 26.2 $(\mathrm{SD}=4.2)$, which is very close to normal (see Table 1 for full details)

Out of the 406 patients with dementia, 300 were of the Alzheimer's type (73.8\%). The least recorded type of dementia was frontotemporal dementia (3.9\%). According to the MMSE score, about half of the patients (49.8\%) had mild dementia, 37.2\% had moderate dementia, and $13.1 \%$ had severe dementia (see Table 2 for full details).

\section{Risk Factors of Dementia}

As mentioned in the method section, each patient with dementia was matched with a control patient free of 
Table I Baseline Characteristics

\begin{tabular}{|c|c|c|c|c|}
\hline Risk Factors & $\begin{array}{l}\text { Dementia Group }(n=406) \text { Frequency } \\
(\%)\end{array}$ & $\begin{array}{l}\text { Control Group }(n=416) \text { Frequency } \\
(\%)\end{array}$ & Test & P-value \\
\hline \multicolumn{5}{|c|}{ Quantitative variables** } \\
\hline Age & $74.4(8.2)$ & $68(7.5)$ & $t$-test & $P<0.00 I^{*}$ \\
\hline Number of comorbidities & $1.93(1.1)$ & $2.05(I)$ & $t$-test & 0.12 \\
\hline Body mass index & $26.21(4.2)$ & $29.04(5.1)$ & $t$-test & 0.09 \\
\hline \multicolumn{5}{|c|}{ Qualitative variables } \\
\hline Gender & & & Chi-square & $0.014 *$ \\
\hline Male & $286(70.4)$ & $258(62.3 \%)$ & & \\
\hline Female & $120(29.6)$ & $156(37.7 \%)$ & & \\
\hline Marital status & & & Chi-square & 0.18 \\
\hline Married & $318(78.3)$ & $342(82.6)$ & & \\
\hline Single & $12(3)$ & $0(0)$ & & \\
\hline Widow/er & $76(18.7)$ & $68(16.4)$ & & \\
\hline Divorced & $0(0)$ & $4(1)$ & & \\
\hline $\begin{array}{l}\text { Family history of } \\
\text { dementia }\end{array}$ & & & Chi-square & $P<0.00 I^{*}$ \\
\hline Yes & $162(399)$ & $18(4.3)$ & & \\
\hline No & $244(60.1)$ & $396(95.7)$ & & \\
\hline Literacy & & & Chi-square & $P<0.00 I^{*}$ \\
\hline Illiterate & $124(30.5)$ & $85(14)$ & & \\
\hline Literate & $282(69.5)$ & $356(86)$ & & \\
\hline Smoking & & & Chi-square & $0.004^{*}$ \\
\hline Never smoked & $2 \mid 4(52.7)$ & $272(65.7)$ & & \\
\hline X smoker & $106(26.1)$ & $56(13.5)$ & & \\
\hline Smoker & $88(21.2)$ & $86(20.8)$ & & \\
\hline
\end{tabular}

Notes: *Significant, **data expressed as mean (standard deviation).

dementia from the same age group. In the current work, 416 patients agreed to participate in the study as controls (Table 1). Results from the univariate analysis showed that patients with dementia were significantly older, of the male gender, had a family history of dementia, were illiterate, and were smokers. Marital status, BMI, and the number of comorbidities were not statistically different between the two groups. Comorbidities such as diabetes, heart disease, and brain attack were not significant between the two study groups and were not presented in Table 1.

Variables in Table 1 were further analyzed using multivariate analysis. The final logistic regression model (Table 3) revealed that the following variables predicted a higher risk of having dementia: older age, male gender, family history of dementia, and illiteracy. Other variables, namely: marital status, number of comorbidities, and smoking, did not predict the risk of dementia, and therefore were not considered as risk factors.

\section{Discussion}

Demographics of the world are changing; people are living to older ages than before. As a result, this will affect the prevalence and incidence of dementia. In Jordan, where this study was conducted, the aging population has increased by $60 \%$ in the last ten years. ${ }^{18}$ As a result, the number of people with dementia is expected to increase due to the established link between old age and dementia. ${ }^{19}$ This information is not yet supported with regard to Jordan due to the gap in knowledge in this area. Therefore, the current research was conducted using a robust methodology to measure the prevalence of dementia in Jordan and explore accompanying risk factors.

The study used a prospective approach by surveying all patients admitted to two of the largest referral hospitals in the north of Jordan, where a large proportion of the population resides. To our knowledge, this study is the first in the region to use a prospective design survey to measure 
Table 2 Description of Dementia $(\mathrm{N}=3 \mathrm{I}, 4 \mathrm{II}))$

\begin{tabular}{|l|l|}
\hline Incidence & $\mathbf{n}(\%)$ \\
\hline Age $\geq 50$ years & $406(1.29 \%)$ \\
Age $\geq 50$ years (male) & $286(1.47 \%)$ \\
Age $\geq 50$ years (female) & $120(0.99 \%)$ \\
Age $\geq 65$ years & $351(1.94 \%)$ \\
Age $\geq 65$ years (male) & $256(2.22 \%)$ \\
Age $\geq 65$ years (female) & $95(1.44 \%)$ \\
Age $\geq 50,<65$ years & $55(0.41 \%)$ \\
Age $\geq 50,<65$ years (male) & $37(0.46 \%)$ \\
Age $\geq 50,<65$ years (female) & $18(0.32 \%)$ \\
Age $\geq 65,<80$ years & $229(1.91 \%)$ \\
Age $\geq 65,<80$ years (male) & $179(2.5 \%)$ \\
Age $\geq 65,<80$ years (female) & $50(1.53 \%)$ \\
Age $\geq 80$ years & $122(2.01 \%)$ \\
Age $\geq 80$ years (male) & $70(2.53 \%)$ \\
Age $\geq 80$ years (female) & $52(1.57 \%)$ \\
\hline Types of dementia & \\
Alzheimer's disease & $300(73.89 \%)$ \\
Vascular & $24(5.91 \%)$ \\
Lowey bodies & $34(8.37 \%)$ \\
Fronto-temporal & $16(3.94 \%)$ \\
Parkinson dementia & $32(7.88 \%)$ \\
\hline MMSE categories & \\
Mild dementia & $202(49.8 \%)$ \\
Moderate dementia & $151(37.2 \%)$ \\
Sever dementia & $53(13.1 \%)$ \\
\hline & \\
\hline
\end{tabular}

the annual period prevalence of dementia, with the total number of dementia cases being the numerator and the total number of admitted to the hospital being the denominator. The two hospitals' electronic medical systems allowed the research team to identify patients and examine them precisely. Further, it enabled the team not to count patients more than once because they can be admitted to the hospital more than once during the study period, ie, one year. This treated the inherent weakness of period prevalence, which is reoccurrence. Diagnosis of dementia was made through a qualified neurologist; this increased the diagnosis's reliability and increased the study results' reliability.

The general prevalence of dementia in the current study for patients 50 years or older was $1.29 \%$, while this number increased to $1.94 \%$ for patients 65 years or older. When this number is compared to global figures, it seems lower than comparable studies that used the same approach. In a meta-analysis for studies using annual period prevalence, the pooled annual prevalence of dementia in people 60 years and over was $6.9 \%{ }^{20}$ Other studies using different methodological approaches also reported a higher number. In a national survey conducted in Iran using random sampling, the prevalence for people 60 years or older was $7.9 \% .^{21}$ Another study reported a lower number, ie, $3.2 \%$, for people above 60 years; however, most of the sample was well educated, which decreases the risk of dementia. One study conducted to measure dementia in Israel's elderly Arab population found the prevalence to be $20.5 \%$. This number is much higher than current study. ${ }^{17}$ However, the population under study had several risk factors that can increase the prevalence of dementia. It can be noticed that different studies using different methodological approaches reported prevalence figures higher than the current study. This could be attributed to the relatively younger Jordanian population compared to populations from other countries described in these studies. $^{18,22}$

Having said that, one should always be cautious in comparing prevalence rates for dementia across studies as differences between estimates may be an actual difference and reflect difference in risk factors but may also reflect methodical or diagnostic issues.

In the current study, the multivariate analysis results (logistic regression) shown in Table 3 were used to determine the risk factors of dementia because they are more valid. The multivariate analysis controls the effect of other

Table 3 Final Logistic Regression Model for Dementia Risk Factors Dementia Group ( $n=406)$, Control Group ( $n=416$ )

\begin{tabular}{|l|l|l|l|l|l|}
\hline Risk Factors & B & df & P value & Odds Ratio & 95\% Confidence Intervals \\
\hline Age & 0.10 & $\mathrm{I}$ & $\mathrm{P}<0.00 \mathrm{I}^{*}$ & 1.10 & -0.19 to 0.39 \\
Gender & 0.67 & $\mathrm{I}$ & $0.003^{*}$ & 3.08 & 0.37 to 0.96 \\
Marital status & 20.08 & 3 & 0.99 & 3.8 & 19.7 to 20.2 \\
Number of comorbidities & -0.06 & $\mathrm{I}$ & 0.48 & 0.94 & -0.23 to 0.35 \\
Family history of dementia & -2.72 & $\mathrm{I}$ & $\mathrm{P}<0.00 \mathrm{I}^{*}$ & 0.06 & 2.42 to $30 \mathrm{I}$ \\
Literacy & 0.97 & $\mathrm{I}$ & $\mathrm{P}<0.00 \mathrm{I}^{*}$ & 2.65 & 0.67 to 1.26 \\
Smoking & -0.36 & 2 & 0.26 & 0.69 & 0.06 to 0.65 \\
\hline
\end{tabular}

Note: *Significant. 
variables when predicting which risk factors are associated with the outcome. Results from the univariate analysis in Table 1 presume that the outcome variable is affected by only one variable at a time, not considering the effect of other variables in the data set. ${ }^{23}$ Results of univariate analysis are shown here to give the reader a picture of the differences between cases and controls in the study sample.

In the current research, older age, male gender, family history of dementia, and illiteracy were risk factors that predicted dementia according to the multivariate analysis results. This result is in line with the literature for the significant study variables, as many studies and reviews reported the same risk factors. ${ }^{11,24}$ On the other hand, marital status (being single), smoking, and the number of comorbidities were reported in the literature to be associated with dementia; in the current study, they were not. One reason for disagreement is that the effect of these modifiable risk factors could differ between different studies because of the different socioeconomic and lifestyle factors of the populations studied. ${ }^{24}$ Most of the studies that reported these factors associated with dementia were conducted in developed countries with different lifestyles and socioeconomic factors thanthe current study population.

Current study results confirm the importance of implementing societal changes and health promotion programs aimed at preventing risk factors associated with dementia. This includes activities toward improving physical, mental, and cognitive health across the health care continuum. This can prevent risk factors associated with dementia, and therefore improve the quality of life of older people, decrease the family care burden, and decrease costs on the health care system.

\section{Limitation}

This study utilized a convenience sampling approach. The sample consisted of people admitted to two hospitals in only one district in Jordan. The study needs to be conducted at a national level to confirm the results.

\section{Conclusion}

This study is the first in the region that used a prospective approach and covered one year to calculate dementia period prevalence and explore predicting risk factors. Study findings demonstrated a markedly lower prevalence than the global one, which could be attributed to the relatively younger Jordanian population when compared to other studies. This low prevalence should not stop prevention and services development for people with dementia, as this number is expected to increase as the Jordanian population is expected to grow older, as forecasted by the census.

\section{Statement of Ethics}

Ethical approval was obtained from Jordan University of Science and Technology and from the ethics committees at King Abdullah University Hospital and Princess Basma Hospital. Patients' identities were anonymous, and medical record numbers were deleted after data were checked and analyzed. Information obtained will not be used for reasons other than scientific research. Ethical approval number: IRB 23/123//2019. This study was conducted in accordance with the Declaration of Helsinki.

\section{Author Contributions}

All authors contributed to data analysis, drafting or revising the article, have agreed on the journal to which the article will be submitted, gave final approval of the version to be published, and agree to be accountable for all aspects of the work.

\section{Funding}

The research team would like to thank the Deanship of Research at Jordan University of Science and Technology for funding this research (Research grant number:20 190243).

\section{Disclosure}

All authors have disclosed no conflicts of interest for this work.

\section{References}

1. Iadecola C. The pathobiology of vascular dementia. Neuron. 2013;80 (4):844-866.

2. Prince M, Bryce R, Albanese E, et al. The global prevalence of dementia: a systematic review and metaanalysis. Alzheimers Dement. 2013;9(1):63-75. e2. doi:10.1016/j.jalz.2012.11.007

3. Tariq S, Barber PA. Dementia risk and prevention by targeting modifiable vascular risk factors. J Neurochem. 2018;144(5):565-581. doi:10. $1111 /$ jnc. 14132

4. Islamoska S, Ishtiak-Ahmed K, Hansen ÅM, et al. Vital exhaustion and incidence of dementia: results from the Copenhagen City heart study. J Alzheimers Dis. 2019;67(1):369-379. doi:10.3233/JAD-180 478

5. Homma A. Diagnostic criteria for age-associated dementia. Japan Med Assoc J. 2001;44(9):409-416.

6. Livingston G, Lee N. The lancet standing commission on dementia prevention, intervention and care 2020-the launch. In: 2020 Alzheimer's Association International Conference. 2020. ALZ.

7. WHO. Risk reduction of cognitive decline and dementia; 2020. Available from: https://www.who.int/mental_health/neurology/demen tia/guidelines_risk_reduction/en/. Accessed February 13, 2021 
8. Ritchie K, Kildea D. Is senile dementia" age-related" or" ageingrelated"? - evidence from meta-analysis of dementia prevalence in the oldest old. Lancet. 1995;346(8980):931-934. doi:10.1016/S01406736(95)91556-7

9. Plassman BL, Langa KM, Fisher GG, et al. Prevalence of dementia in the United States: the aging, demographics, and memory study. Neuroepidemiology. 2007;29(1-2):125-132. doi:10.1159/000109998

10. Hudomiet P, Hurd M, Susann R. Dementia prevalence in the United States in 2000 and 2012: estimates based on a nationally representative study. J Gerontol. 2018;73(s1):S10-S19. doi:10.1093/geronb/gbx 169

11. Wu Y-T, Ali G-C, Guerchet M, et al. Prevalence of dementia in mainland China, Hong Kong and Taiwan: an updated systematic review and meta-analysis. Int $J$ Epidemiol. 2018;47(3):709-719. doi:10.1093/ije/dyy007

12. Kalaria RN, Maestre GE, Arizaga R, et al. Alzheimer's disease and vascular dementia in developing countries: prevalence, management, and risk factors. Lancet Neurol. 2008;7(9):812-826. doi:10.1016/ S1474-4422(08)70169-8

13. Ohara T, Hata J, Yoshida D, et al. Trends in dementia prevalence, incidence, and survival rate in a Japanese community. Neurology. 2017;88(20):1925-1932. doi:10.1212/WNL.0000000000003932

14. Roehr S, Pabst A, Luck T, et al. Is dementia incidence declining in high-income countries? A systematic review and meta-analysis. Clin Epidemiol. 2018;10(2):1233. doi:10.2147/CLEP.S163649

15. Prince M, Ali G-C, Guerchet M, et al. Recent global trends in the prevalence and incidence of dementia, and survival with dementia Alzheimers Res Ther. 2016;8(1):23. doi:10.1186/s13195-016-0188-8
16. Kodesh A. Prevalence and comorbidities of dementia in Israel: a nationally representative cohort study. Int Psychogeriatr. 2018; 1-5. doi:10.1017/S1041610218001461

17. Bowirrat A, Treves TA, Friedland RP, et al. Prevalence of Alzheimer's type dementia in an elderly Arab population. Eu J Neurol. 2001;8(2):119-123. doi:10.1046/j.1468-1331.2001.00183.x

18. DOS. Old age in Jordan; 2019; Available from: http://dosweb.dos. gov.jo/ar/persons_201809/. Accessed February 13, 2021.

19. Jones SV, O'brien J. The prevalence and incidence of dementia with Lewy bodies: a systematic review of population and clinical studies. Psychol Med. 2014;44(4):673-683. doi:10.1017/S0033291713000 494

20. Fiest KM, Jetté N, Roberts JI, et al. The prevalence and incidence of dementia: a systematic review and meta-analysis. Can J Neurol Sci. 2016;43(1):S3-S50. doi:10.1017/cjn.2016.18

21. Sharifi F, Fakhrzadeh H, Varmaghani M, et al. Prevalence of dementia and associated factors among older adults in Iran: national Elderly Health Survey (NEHS). J Arch Iran Med. 2016;19(12).

22. WHO. Dementia; 2020. Available from: https://www.who.int/newsroom/fact-sheets/detail/dementia. Accessed February 13, 2021.

23. Field A. Discovering Statistics Using IBM SPSS Statistics: North American Edition. sage; 2017.

24. Deckers K, Cadar D, van Boxtel MPJ, et al. Modifiable risk factors explain socioeconomic inequalities in dementia risk: evidence from a population-based prospective cohort study. J Alzheimers Dis. 2019;71 (2):549-557. doi:10.3233/JAD-190541
International Journal of General Medicine

\section{Publish your work in this journal}

The International Journal of General Medicine is an international, peer-reviewed open-access journal that focuses on general and internal medicine, pathogenesis, epidemiology, diagnosis, monitoring and treatment protocols. The journal is characterized by the rapid reporting of reviews, original research and clinical studies across all disease areas. The manuscript management system is completely online and includes a very quick and fair peer-review system, which is all easy to use. Visit http://www.dovepress.com/ testimonials.php to read real quotes from published authors. 